\title{
Pattern-directed Auditing of Inter-organisational Trade Procedures
}

\author{
Ronald M. Lee ${ }^{1}$, Roger W.H. Bons ${ }^{2}$, René W. Wagenaar ${ }^{3}$ \\ ${ }^{1}$ Erasmus University Research Institute for Decision and Information Systems (EURIDIS), The \\ Netherlands; \\ ${ }^{2}$ Philips International BV - Corporate IT, eBusiness Support Strategy and Planning, Eindhoven, \\ The Netherlands;
}

${ }^{3}$ Rotterdam School of Management, Dept. Decision and Information Systems, Erasmus University Rotterdam

\begin{abstract}
In open business-to-business electronic commerce, when trading with parties where no prior trade relationships or trust exist, the parties need to rely on inter-organizational trade procedures that control trading risks. These trade procedures have to be audited to identify potential control weaknesses and the resulting fraud potential, including the risks associated with the communication medium used to support the execution of these procedures.

This article is an initial step towards establishing a theory on the auditing of inter-organizational (trade) procedures. A set of generic principles is proposed for inter-organizational trade procedures, which includes the analysis of potential control weaknesses associated with the technical communication infrastructure. We show how this theory can be supported using automated techniques, and illustrate using the example of a documentary credit procedure.
\end{abstract}

\section{THE NEED FOR INTER-ORGANISATIONAL PROCEDURES}

Following the wave of business to consumer (B2C) electronic commerce, the focus is now shifting to business to business applications. In this article the object of analysis are the procedures used to exchange the information that is needed for the execution of a business transaction.

More and more, these procedures are becoming automated, in the form of electronic trade procedures, that are generic and re-usable among different sets of 
parties. Reaching agreement on how to use electronic trade procedures not only involves the design of an acceptable procedure to be used, but also involves detailed legal and technical arrangements. Since in most countries an electronic message (business document) is not by default acceptable in a court of law, a specific contract $^{26}$ has to be made to deal with any legal problem that might arise from replacing traditional paper documents with electronic messages. The process of reaching these agreements can become quite costly and introduces a highly relationship-specific cost in the establishment of an electronic link between trading partners.

These high relationship-specific costs associated with electronic messaging have resulted in a situation in which it has been applied mainly for long-term, stable trading relationships among trusting partners. The procedures used in these relationships focus on reducing the co-ordination costs the parties have to incur for exchanging their products or services. For instance, logistical concepts such as Just In Time delivery are highly supported by the electronic exchange of (operational) data. If something goes wrong during the transaction, the parties will jointly try to find a solution that does not endanger the continuation of their long-lasting relationship.

However, increasingly dynamic competition and globalization are pushing for a more open form of business-to-business electronic messaging -- that is applicable in shorter term relationships involving a small number of transactions and without a pre-existing trust among the parties. As in the past, such new forms of messaging will continue to require detailed specification of the procedures to be used to exchange the messages. However, the negotiation costs to agree upon these procedures should be minimized in order to lower the entry barriers.

An example of an approach that could contribute to the lowering of these negotiation costs is the notion of electronic trade procedures, as being developed by the Business Process Analysis Group (BPAWG), of the United N Ations Center FOR TRAde Facilitation AND Electronic B USiness (UN/CEFACT). A related concept is that of "Open-edi" as defined by the International Standards Organization (ISO) working group (IEC JTC1/SC30/SC32). This initiative strives towards the construction of tools for the standardization of inter-organizational procedures, using formal specifications of these procedures (called "Open-edi Scenarios", [ISO, 1996]).

However, in these more open kinds of circumstances, where the trading partners do not know or fully trust each other, they will require more 'control information' about each other's behavior during the execution of a transaction. Parties may be subject to opportunistic behavior of their counter-party, yielding a clear and present danger of loosing money. Thus, if parties cannot trust each other, they have to be able to rely on the procedures they use to interact.

In international trade, this has lead to well-established (paper-based) procedures controlling with these risks and the introduction of parties such as inspection agencies and banks to serve as trusted intermediaries. An example of such a procedure is the Documentary Credit procedure [ICC, 1994], which is discussed in more detail below. Other examples include the Incoterms, which standardize the 
delivery terms in a sales contract [ICC, 1990] and (inter)national customs procedures.

In order to support the formal specification of inter-organizational procedures, our previous research has resulted in the Documentary Petri Net (DPN) formalism. This formalism builds upon classical Petri Nets [Petri, 1962; Peterson, 1981], with some extensions to enable the modeling of electronic trade procedures. Each of the roles is modeled as a separate DPN model. The transitions of the Petri Net represent the activities to be performed within the role. In addition to the classical Petri Net, two additional types of places are introduced: document places and goods places. They are introduced to make a clear graphical distinction between control places and places that represent the transfer of information or goods. The interested reader is referred to [Lee, 1999; 2000] for a more extensive discussion on the DPN formalism.

These DPN models are built using the CASE tool InterProcs ${ }^{27}$, a modeling tool developed by Lee [1992, 1999, 2000]. InterProcs offers a graphical user interface with which Documentary Petri Nets can be drawn. Furthermore, since InterProcs embeds a Prolog engine, rule-bases can be added to a Documentary Petri Net model, allowing automatic reasoning about modeled trade procedures. The pattern recognition approach presented below is an example of this.

Summarizing this first section, we have identified the need for the specification of inter-organizational procedures. Such procedures have existed for centuries in the paper-based world, but their importance increases now the world has entered the era of electronic commerce. Especially when non-trusting trading partners are doing business with each other, they have to have a clear understanding of the procedures they are going to use to govern their transactions. This will lead toward a further rtionaliztion and formalization of inter-organizational trade procedures. To support this process, our previous research resulted in the Documentary Petri Net formalism and the InterProcs tool. In this article, we introduce a theory for auditing inter-organizational procedures to assess their trustworthiness.

\section{THE AUDITING OF INTER-ORGANISATIONAL PROCEDURES.}

With the emergence of electronic commerce companies may quickly encounter new ways of doing business. Not only will they be able to do business with companies from different (trading) cultures, but also the type of business may differ.' An example of the latter is the purchase of multi-media data (music, books etc.), in which not only the purchasing, but also the actual delivery process is conducted through an electronic network. Trading parties must be able to rely on the ability of the procedures governing their transactions to control the risks associated with doing business at arms' length.

27 InterProcs was originally developed in Prolog, but has since been re-implemented in Java, providing for operational models both as executable applets and for standalone design. The current version of InterProcs is available at the Web site: http://abduction.euridis.fbk.eur.nVprojects/Znrocs.html. 
In addition to this, the character of the controls could change as well. Using modern technology, the traditional paper-based controls could be replaced by more efficient and/or effective electronic controls. In the Port of Rotterdam, several pilot studies have shown that huge benefits can be achieved, both with respect to cost savings in the execution of the controls and cost savings related to a better management of the risks (less damage).

It is clear from the previous discussion that the assessment of the trustworthiness of inter-organizational procedures becomes a crucial factor in the successful adoption of these procedures. Developments in (open) electronic commerce not only require the porting of existing, paper-based, procedures into an electronic setting, but also trigger the development of totally new procedures. Our research offers the first steps towards the establishment of a theory on inter-organizational auditing.

Participants in business transactions will strive to reduce the risk of nonperformance by implementing inter-organizational controls. An obvious way to do this is to conduct business only with those parties one trusts. However, in the open trading relationships this trust is typically not present and the risks have to be reduced by exchanging additional control information. Parties fully depend on the reliability of the messages received when deciding whether or not they have to perform some activity. If the underlying message was wrong or manipulated, this can lead to a substantial loss for that party.

In the linguistic philosophy literature, this control functionality of information has been referred to as 'Speech Acts' [Austin, 1962; Searle, 1969]. This theory deals with 'performative documents', which change the 'societal state' of the parties exchanging them. For instance, a party making an offer towards another party has created a conditional obligation by sending such a message. With respect to the performative function of EDI messages, several authors have proposed a taxonomy of different classes of messages (see for instance [Lee, 1992; Moore, 1996]).

Based on parallels with internal accountancy theory, we have constructed an initial set of 'general principles' for the construction of safe trade procedures, based on principles in the internal auditing literature. These modifications solely consist of the replacement of the internal auditing terms 'operational task', 'control task', 'document', 'agent' and 'position' with 'primary activity', 'control activity', 'information parcel', 'organization' and 'role' respectively. We do not claim the completeness of this list; its sole function is to provide a starting point for further research. For instance, existing rules on collusion between agents in internal auditing literature can be easily translated into rules for collusion between companies, resulting in fraud schemes.

1. If a primary activity is performed by one role, another role should testify the completion thereof using some information parcel. The primary activity should precede the control activity. The role responsible for the control activity should be different from the role executing the primary activity. Furthermore, the organizations playing the roles should not be connected.

2. If a role executes a primary activity and some information parcel is issued by another role to testify this, this information parcel should be received by the 
executing role as well. This principle constitutes the detective controls as mentioned in the previous sections

3. If a role A executes a primary activity, the result of which triggers the execution of another primary activity in a role $\mathrm{B}$, an information parcel must be issued by another role $\mathrm{C}$ to testify this if role $\mathrm{B}$ cannot witness the execution of role A's activity. This document must be received and checked by role B.

4. If a certain item (goods/funds) is physically transferred from on role to another, the receiving role must identify itself using some document. This transfer should occur after the identification took place.

5. If a certain item is physically transferred from one role to another, the receiving role should certify the status of the item as it is received using some document. The transfer of this document and the exchange of the item should occur simultaneously.

6. If an intermediary organization is used for the (physical) transfer of an item, a report should be received by the principal from both the intermediary agent and the receiver of the item.

\section{COMPUTER AIDED SUPPORT FOR THE AUDITING OF INTER-ORGANISATIONAL PROCEDURES}

\subsection{A Pattern Recognition Approach For Internal Auditing}

In this section we will introduce the computational technique of "audit daemons" (Lee, 1991), which was applied to internal auditing in the dissertation work of Chen (1992). The purpose of Chen's work was to "develop a theoretical foundation for building a knowledge-based system, which can accept a model of an internal accounting control system as input and produce the identification of fraud potentials as output". Chen based his theory on a schema-based reasoning approach, integrating the schema theory of knowledge representation from cognitive psychology and pattern recognition in the field of Artificial Intelligence. The internal accounting control system is modeled using the Documentary Petri Net (DPN) formalism.

The knowledge base containing the general principles for internal auditing is constructed as follows. Chen starts by identifying control patterns of accounting procedures. Control patterns are "stereotypical relationships between agents, tasks, and information repositories". They serve as "screening criteria for auditors to identify control weaknesses". The control patterns are based on the control objectives to be achieved over the operating tasks and are represented using a logicbased language. 
These control patterns serve as the starting point for the auditing process as they specify the way it ought to be. Deviations of such control patterns (control weaknesses) are called "audit patterns". If a pattern of a control weakness is recognized in a given internal accountancy control system, a warning has to be raised. Since the control patterns are specified using a logic-based language, the audit patterns can be easily inferred from the control patterns using a logical negation. This process is followed on all the control patterns specified, resulting in a set of audit patterns.

The audit patterns in their turn are used to identify the illegal actions that could be taken by an agent in charge of an operating task. For this purpose Chen introduces audit rules, which take the audit patterns as their antecedent and contain explicit warnings as their consequent, which have to be pronounced by the system in case they are matched.

The automated evaluation process takes these audit rules and a Petri Net model of an internal accounting control system as input. For this purpose Chen identified "control primitives", which are in fact the conditions in the audit rules. $\mathrm{He}$ distinguishes "procedural control primitives" and "organizational control primitives". The organizational control primitives are checked using the organizational structure of the control system. The procedural control primitives have to be checked by analyzing the Petri Net model of the internal accounting control system. Pattern recognition is used to map the Petri Net model to the control primitives as they are found in the rules. These control primitives are represented as 'audit daemons'. Figure 1 shows the audit daemons for the control primitives $\operatorname{task}(\mathbf{X}: \mathbf{A})$ and the follows $(\mathbf{X}: \mathbf{A}, \mathbf{Y}: \mathbf{B})$ primitives as they were used by Chen.

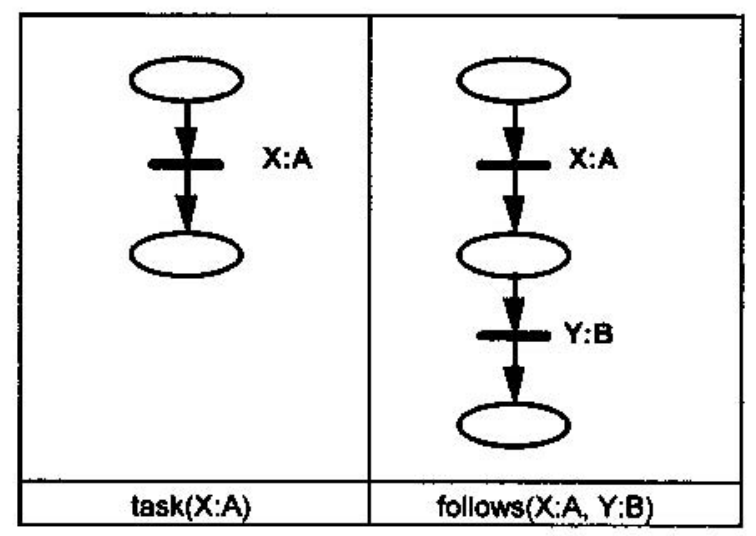

Figure 1. Two examples of audit daemons

This concludes our review of Chen's analysis approach. In the next section the application of this approach in the domain of inter-organizational trade procedures is addressed. 


\subsection{The Pattern Recognition Approach Applied To Inter-Organizational Procedures}

In this section the analysis method of Chen is applied to the inter-organizational context. First some of Chen's definitions are adapted for the inter-organizational context. The set of conditions that have to be evaluated for the audit rules in this example consists of the following predicates:

\subsection{The Pattern Recognition Approach Applied To Inter-Organizational Procedures}

In this section the analysis method of Chen is applied to the inter-organizational context. First some of Chen's definitions are adapted for the inter-organizational context. The set of conditions that have to be evaluated for the audit rules in this example consists of the following predicates:

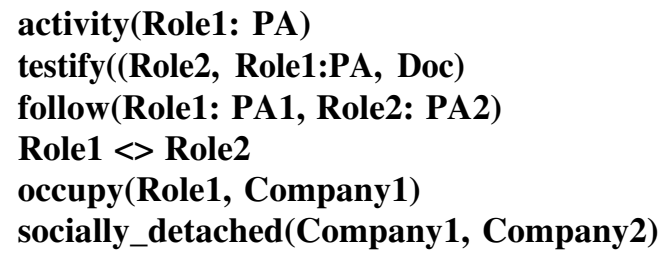

These conditions have to be evaluated based on the DPN model of the procedure under investigation. The conditions 'activity', 'testify' and 'follow' are procedural control primitives, whereas 'occupy', 'principal', '<>' and 'socially_detached' are organizational control primitives. The procedural control primitives are checked using audit daemons (see Figure 1), the organizational control primitives are checked based on the underlying logic-based language representation. It should be noted that for the control conditions referring to a performative action (in this case 'testify') a more detailed description may be used, in terms of a procedural audit daemon. For instance, in case of the certification of goods, the Communication Chain for transferring a certificate of origin from the inspection agency to the consignee satisfies the predicate

testify(inspection_agency, shipper: produce_goods, certificate _of_origin).

\section{EXAMPLE: THE DOCUMENTARY CREDIT PROCEDURE.}

In order to illustrate how the analysis process can be supported by an automated tool, this section contains a small example of the documentary credit procedure. This 
is a procedure that facilitates the exchange of goods against money between a buyer and seller who do not trust each other completely. It is fully governed by the exchange of (performative!) documents that control the behaviour of the seller on behalf of the buyer.

The seller has to obtain these documents and present them to his bank. All parties have an underlying contract (the Letter of Credit), which specifies exactly which documents are requested, based on the underlying sales contract. Upon presentation of a correct set of documents, the 'corresponding bank' will pay the seller. In its turn, the corresponding bank will be able to retrieve its money from the issuing bank by forwarding the documents.

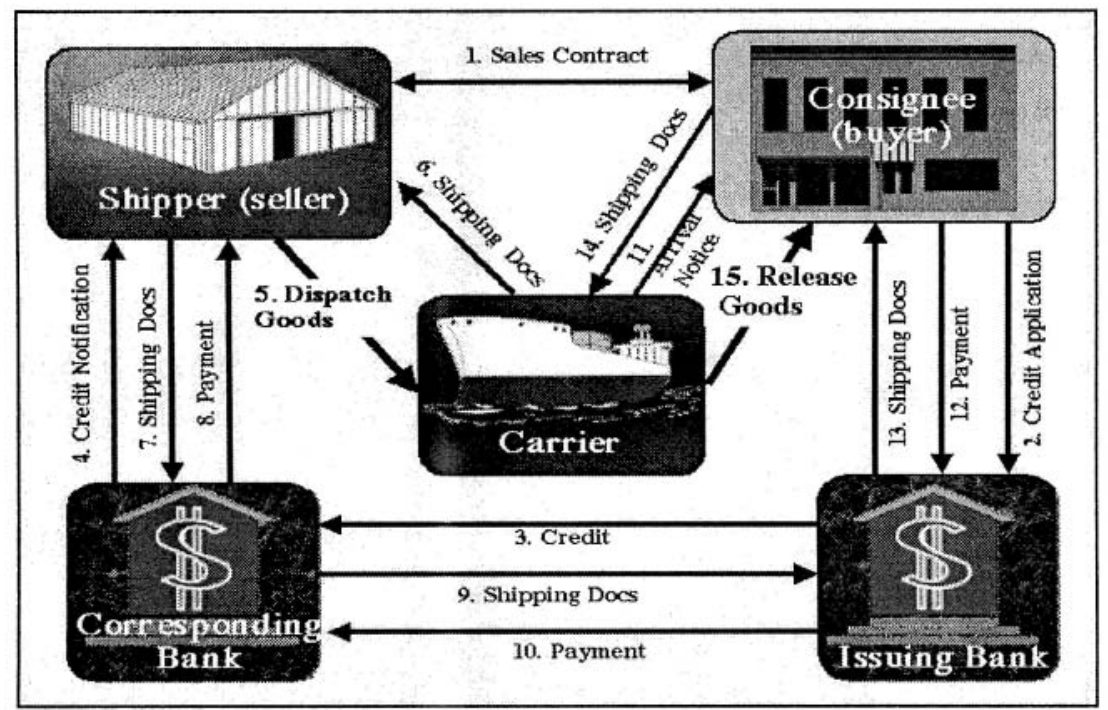

Figure 2. A Simplified Documentary Credit Procedure

Finally, the issuing bank will forward the documents to the buyer in exchange for the price. Note that the buyer needs these documents to be able to claim the goods once they arrive at the port (especially the 'bill of lading' is used for this purpose). The procedure is still fully based on paper, and is usually only used for large transactions.

Instead of the informal specification in Figure 2, the formal analysis requires the specification of an trade procedure in terms of roles and information parcels. In Figure 3, the DPN role model for the seller (called 'shipper') is shown as an example. Similar models are constructed for the other roles as well. The individual role models are 'glued' together at their document/goods places, representing the inter-organizational exchanges of information. 


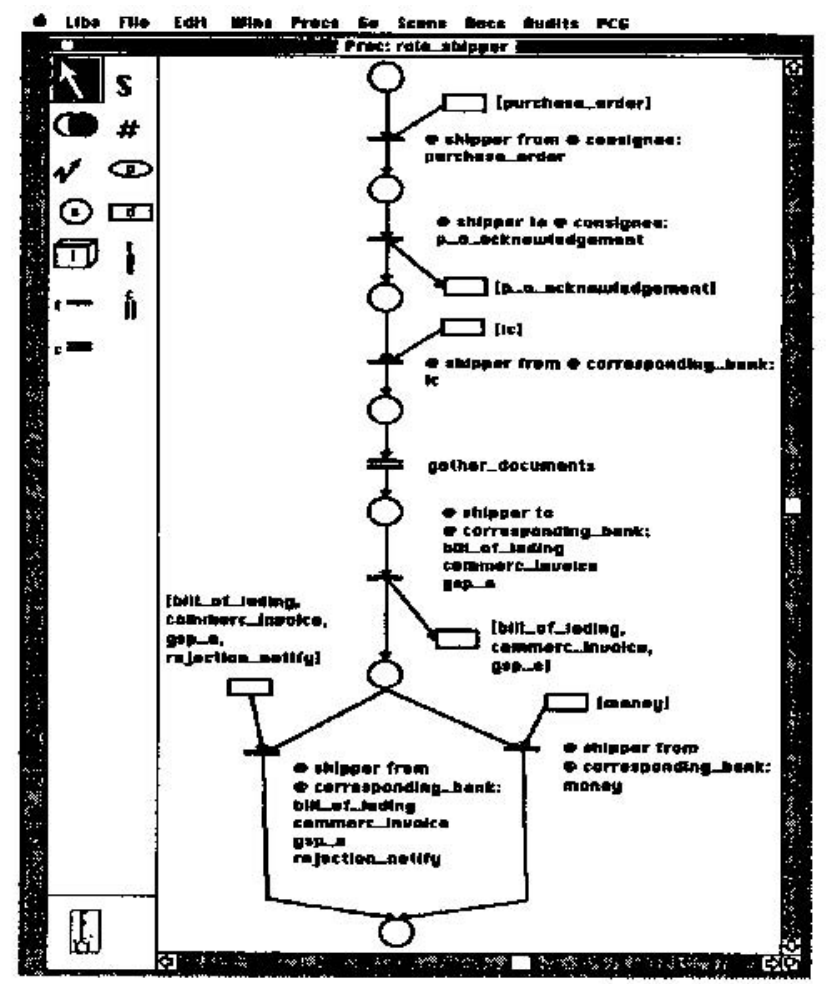

Figure 3. The DPN model of the shipper role

As a next step, the general principles presented above are instantiated in order to be usable in this domain. This is done using the Table 1, which is the result of a literature review in this area (especially the Incoterms [ICC, 1990]). It lists the primary activities governed by the documentary credit procedure, specifies the documents needed to control them and identifies the roles responsible for performing these controls. 


\begin{tabular}{|c|c|c|}
\hline $\begin{array}{c}\text { PRIMARY } \\
\text { ACTIVITY }\end{array}$ & $\begin{array}{c}\text { CONTROL } \\
\text { DOCUMENT }\end{array}$ & $\begin{array}{c}\text { CONTROLLI } \\
\text { NG PARTY }\end{array}$ \\
\hline $\begin{array}{c}\text { producing the } \\
\text { goods }\end{array}$ & certificate of origin & $\begin{array}{c}\text { inspection } \\
\text { agency }\end{array}$ \\
\hline $\begin{array}{c}\text { packaging the } \\
\text { goods }\end{array}$ & $\begin{array}{c}\text { certificate, packing } \\
\text { list, b/l }\end{array}$ & $\begin{array}{c}\text { inspection } \\
\text { agency, carrier }\end{array}$ \\
\hline $\begin{array}{c}\text { arranging } \\
\text { transportation }\end{array}$ & $\begin{array}{c}\text { b/l, CMR, airwaybill, } \\
\text { CTA }\end{array}$ & carrier \\
\hline $\begin{array}{c}\text { paying the } \\
\text { transportation }\end{array}$ & $\begin{array}{c}\text { b/l, CMR, airwaybill, } \\
\text { CTA }\end{array}$ & carrier \\
\hline $\begin{array}{c}\text { arranging } \\
\text { insurance }\end{array}$ & $\begin{array}{c}\text { insurance contract } \\
\text { delivering the } \\
\text { goods to carrier }\end{array}$ & $\begin{array}{c}\text { b/l, CMR , airwaybill, } \\
\text { company }\end{array}$ \\
\hline $\begin{array}{c}\text { transferring the } \\
\text { property }\end{array}$ & $\begin{array}{c}\text { b/l, CMR, airwaybill, } \\
\text { CTA }\end{array}$ \\
\hline
\end{tabular}

Table 1: Relationship between primary activities and control documents used to control them.

The generic rules presented earlier can now be instantiated with parameters that refer to specific roles and documents as listed in Table $1^{28}$. This yields a huge set of rules that have to be satisfied in a proper documentary credit procedure. Note that the rules specified in Table 1 only consider the relationship between buyer and seller and have to be extended to deal with the relationships between these parties and the banks involved.

In this article we use two example cases to illustrate the results of the analysis process. In the first case, the wrong type of document was used to evidence the transfer of the property. The shipper issued a 'delivery order' himself, which did evidence that he gave the assignment to the carrier to transport the goods, but did not provide the buyer with sufficient documentation to claim the goods. In fact, some other party did in fact claim the goods from the carrier instead. The analysis of the DPN model of this situation warns against this possibility since it will not find a proper document to evidence the transfer of the property.

In the second case, an insecure medium was used to transfer the information, which allowed the shipper to forge both the bill of lading and the certificate of origin. A fax message was used to transfer both of these documents. Normally, the receiving party should have rejected this document for exactly this reason. Although this example seems to be irrelevant for the analysis of trade procedures, it does show what can happen if not the proper security measures have been taken. The analysis of the DPN model of this case warns that the technical security requirements (nonrepudiation etc.) have not been fulfilled, since it can not find the proper controlling

${ }^{28}$ The rules for the analysis of the technical infrastructure have been instantiated already since they are not domain specific. 
activities in the specification of the Message Transporting Service used for the transfer of the documents.

\section{CONCLUSIONS AND FUTURE RESEARCH DIRECTIONS.}

The main contribution of this paper was the introduction of a new theory on the auditing of inter-organizational procedures. This entails the analysis of interorganizational trade procedures on how trustworthy they are. Based on the similarities between the analysis of inter-organizational control systems and internal accounting control systems an initial set of generic principles for interorganizational trade procedures has been presented. In addition to this, control weaknesses caused by the use of a communication medium have been addressed in a similar fashion as well.

In order to support this theory, we have extended the InterProcs tool, that uses a pattern recognition approach for the auditing of internal accounting control systems. Since the problem domains are very similar, the same technique could be applied in the inter-organizational context as well. Some minor additions were needed to deal with the complexity of recursive control rules in the area of the technical communication infrastructure. The working of the tool has been briefly illustrated using examples from the documentary credit domain.

Future research has to improve this initial theory based on more empirical knowledge, covering multiple application domains. The list of general principles should be completed and national differences, but also differences per industry, should be reflected in these rules. The communication technologies have not been examined in sufficient detail to claim completeness of the auditing rules on this area either. Several projects are on their way to construct such rules, especially with respect the use of encryption and trusted third parties in electronic commerce.

\section{REFERENCES}

Austin, J.L., How to DO things with words, Harvard University Press, Cambridge, MA, 1962. Bons, R. W.H., Lee, R.M., Wagenaar, R. W., Wrigley, C.D., Modelling Inter-organizational

Trade Procedures Using Documentary Petri Nets, Proceedings Hawaii International Conference on System Sciences (HICSS) 28, Hawaii, USA, pp. III/189-198, January, 1995.

Bons, R.W.H., Lee, R.M., and Wagenaar, R.W. "Computer-Aided Auditing of Interorganizational Trade Procedures", Intelligent Systems in Accounting, Finance and Management, Special Issue on Electronic Commerce, ed. Jae Kyu Lee, 1999

Bons, R.W.H, Dignum, F., Lee, R.M and Tan, Y-H. "A Formal Specification of Automated Auditing of Trustworthy Trade procedures for Open Electronic Commerce", Proceedings of the Hawaii International Conference on System Sciences, January, 1999.

Chen, Kuo-Tay. Schematic Evaluation of Internal Accounting Control Systems,

University of Texas at Austin, USA, PhD Dissertation, 1992. 
Dewitz, S. K., Lee, R. M., Legal Procedures as Formal Conversations: Contracting on a Performative Network, Proceedings of International Conference on Information Systems, Boston, U.S.A., pp. 53-65, December, 1989.

Elsas, P., Computational Auditing, PhD thesis Free University Amsterdam, Netherlands, September, 1996.

Frielink, A.B., De Heer, H.J. (eds.), Leerboek Accountantscontrole, Stenfert Kroese, Volumes I, IIa and IIb, Leiden, Antwerpen, (in Dutch), 1985 (I), 1987 (IIa), 1989(IIb).

Garfunkel, S. , PGP: Pretty Good Privacy, O’Reilly \& Associates, Inc., U.S.A., 1995.

ICC, Incoterms 1990, International Chamber of Commerce publication number 461, 1990.

ICC, The Uniform Customs and Practices for Documentary Credit Procedures, International

Chamber of Commerce publication number 500, Paris, France, January, 1994.

ISO, The Open-edi Conceptual Model, ISO/IEC JTC1/SWG-EDI, Document N222, 1991.

ISO, The Open-edi Reference Model, IS 14662, ISO/IEC JTC1/SC30, 1996.

Lee, R.M., "Auditing as Pattern Recognition: Automated Analysis of Documentary

Procedures", Working Paper, Department of Management Sciences and

Information Systems, University of Texas at Austin, August 1991.

Lee, R.M., Dynamic Modeling of Documentary Procedures: A CASE for EDI, Proceedings of Third International Working Conference on Dynamic Modeling of Information Systems, Noordwijkerhout, Netherlands, June, 1992.

Lee, R.M. "Distributed Electronic Trade Scenarios: Representation, Design, Prototyping", International Journal on Electronic Commerce : Special Issue on Formal Aspects of Digital Commerce, eds. S. O. Kimbough and R.M. Lee, Vol3, No 1, 1999, pp. 23-26.

Lee, R.M. "Documentary Petri Nets: A Modeling Represention for Electronic Trade

Procedures" Business Process Management: Models, Techniques, and Empirical Studies, eds. W. Aalst, J. Desel, A. Oberweis, Springer, 2000, pp. 359-375.

Lee, R.M., Bons, R.W.H., Wrigley, C.D., Wagenaar, R. W., Automated Design of Electronic

Trade Procedures Using Documentary Petri Nets, Proceedings Fourth International Conference on Dynamic Modeling and Information Systems, Noordwijkerhout, Netherlands, pp. 137-150, September, 1994.

Lee, R.M., Bons, R. W.H., Soft-Coded Trade Procedures for Open-EDI, International Journal of Electronic Commerce, pp. 27-50, Volume 1 Number 1, 1996.

Moore, S.A., Testing Speech Act Theory and its applicability to EDI \& other computerprocessable messages, Proceedings of the 29th Hawaii Intenational Conference on System Sciences, Hawaii, U.S.A., pp.30-38, January, 1996.

Peterson, J. L., Petri Net Theory and the Modeling of Systems, Prentice-Hall, 1981.

Petri, C.A., Kommunikation mit Automaten, PhD thesis University of Bonn,, Germany, 1962.

Searle, J., Speech Acts: An Essay in the Philosophy of Language, Cambridge University Press, London, UK, 1969.

Starreveld, R. W., De Mare, H.B., Joëls, E.J., Bestuurlijke Informatieverzorging, Samsom Bedrijfsinformatie, Part I \& II, Alphen a/d Rijn, Netherlands, (in Dutch), 1995.

Van Tulder, R., Wagenaar, R. W. (eds.), Omgaan met Dilemma's: Zeven Cases in Strategie en Informatie Technologie in Mainport Rotterdam, Kluwer Bedrijfswetenschappen, Deventer, Netherlands, (in Dutch), 1995.

Wagenaar, R. W., Business network redesign - Lessons from the Port of Rotterdam Simulation game, Proceedings Conference on interorganizational systems in the global environment, Bled, Slovenia, September, 1992.

Wrigley, C.D., EDI transaction protocols in international trade, Proceedings Conference on interorganizational systems in the global environment, Bled, Slovenia, September, 1992. 